\title{
Editorial Changes at the Journal of Molecular Evolution
}

\author{
Niles Lehman
}

Received: 28 January 2013/Accepted: 30 January 2013/Published online: 8 February 2013

(c) Springer Science+Business Media New York 2013

On January 1, 2013 Martin Kreitman stepped down as editor-in-chief (EIC) of the Journal of Molecular Evolution after 15 years in this role. During this time the rich tradition of this journal has continued, and the readership base has broadened. These have been exciting times in the fields and sub-fields that connect to the topic of molecular evolution. The human genome was completely sequenced, and we have seen an explosion of genomic-wide data, the advent of high-throughput sequencing, fascinating developments in the interface between development and evolution ("evo-devo"), the burgeoning of an understanding of the role of small RNAs in gene regulation, rapid advances in high-throughput X-ray crystallization-based structure determination of both proteins and nucleic acids, sweeping advances in computational hardware and techniques, and the entrenchment of the Internet as the means by which data is stored, analyzed, and shared, and by which scientific publishing is accomplished. Through all of this, Marty has strove to bring the highest quality research to $J M E$, but for personal reasons has chosen to step down as EIC and focus on other issues.

I will become the new EIC for JME after having been an associate editor (AE) with the journal since 1996. I received my B.S. in Chemistry from the University of California, Berkeley in 1984 and stayed on to obtain a Master's degree with Tom Jukes in the Space Sciences Laboratory at Berkeley in 1986, studying the evolution of the genetic code. I was Tom's last graduate student and first became exposed to the rich field of molecular evolution-and to $J M E$ - during my stay in Tom's lab. I then

N. Lehman $(\bowtie)$

Department of Chemistry, Portland State University,

Portland, OR 97207, USA

e-mail: jme1@pdx.edu; niles@pdx.edu moved to UCLA to be one of the first Center for the Study of Evolution and the Origins of Life (CSEOL) Fellows at UCLA, a program founded by J. William Schopf. There I worked with Bob Wayne and Chuck Taylor on the molecular population genetics of canids and received my Ph.D. in 1990. From there I moved on to be a post-doctoral fellow at The Scripps Research Institute in La Jolla, CA, working with Jerry Joyce on the in vitro evolution of the Tetrahymena ribozyme. I then did a second post-doc with Mike Lynch at the University of Oregon studying phylogenetics and speciation in the freshwater microcrustacean Daphnia. After two tenure-track appointments at other universities, I arrived at Portland State University in Portland, Oregon in 2001 where I am now a full professor of Chemistry. My current research focuses on the use of catalytic RNAs to study self-replication, molecular cooperation, and the advent and evolution of genetic information during the origins of life on the Earth. Several Ph.D. students have graduated from my lab at Portland State, supported by funding by through various NASA programs such as Exobiology and Evolutionary Biology.

This editorial change marks only the second one in $J M E$ 's history. The journal was founded in 1971, when Conrad Springer offered Emile Zuckerkandl, who along with Linus Pauling had originated the idea of the molecular clock, the position of EIC (Bernardi 2012). Zuckerkandl accepted, and with a staff of four editors and 41 editorial board members, the journal published its first issue in the summer of 1971. Among the four editors was Dick Dickerson, a pioneer in the study of DNA structure and coincidentally on my Ph.D. committee at UCLA. Another of the editors was Jack Lester King, co-author with Tom Jukes of a classic 1969 paper entitled "Non-Darwinian Evolution" (King and Jukes 1969), which helped to define the study of molecular evolution. The editorial board 


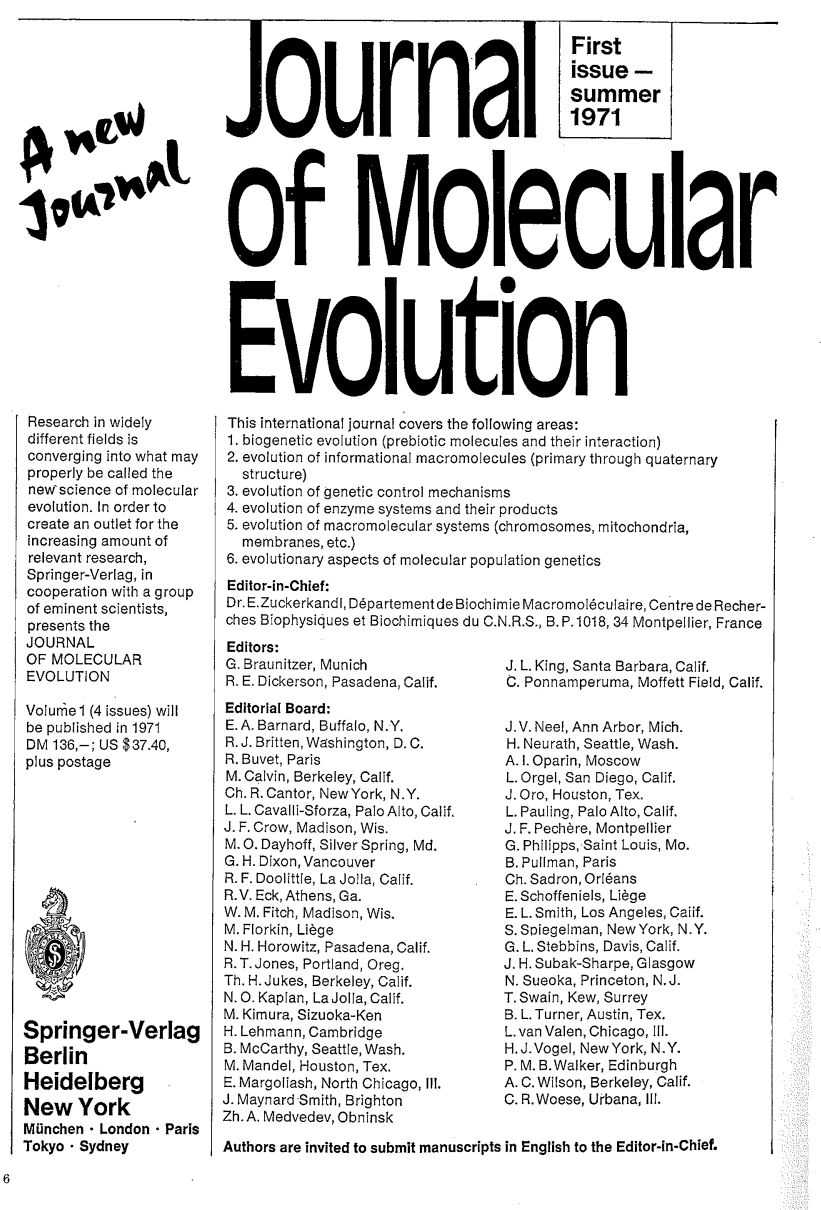

\section{DIE NATURWISSENSCHAFTEN \\ 58. Jahrgang, 1971 \\ Heft 10 Oktober}

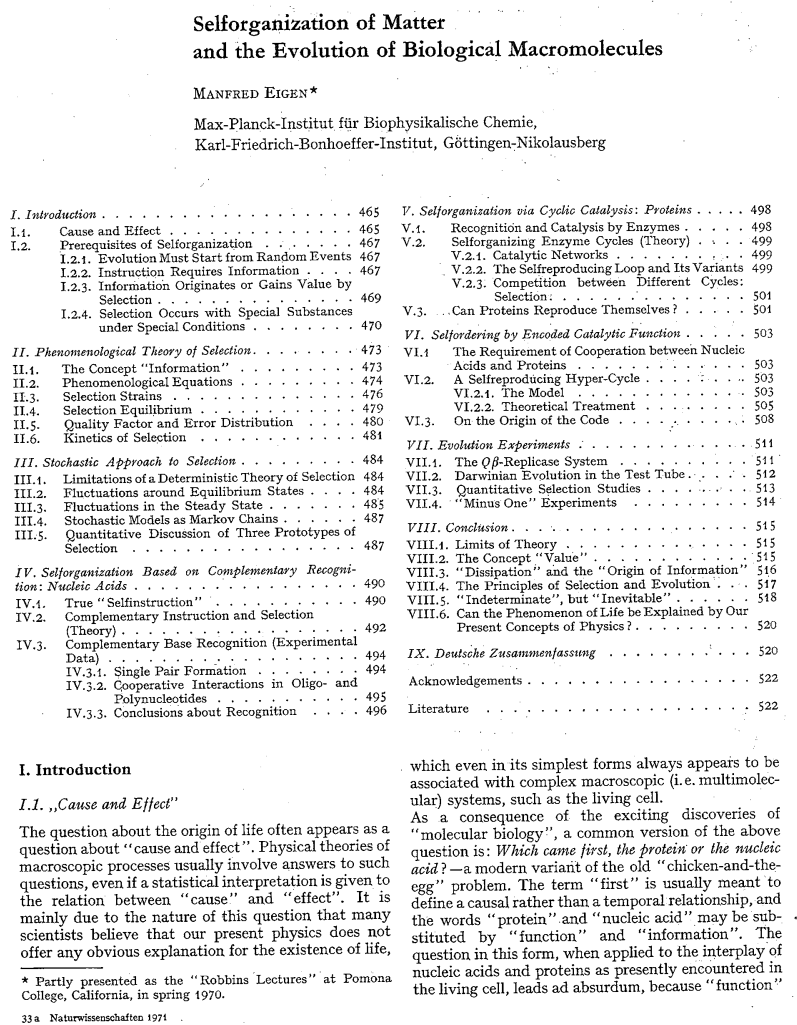

Fig. 1 Advertisement for a "new journal" (JME) as it appears in the October 1971 issue of Die Naturwissenschaften immediately opposite the first page of Manfred Eigen's (1971) groundbreaking treatise on molecular evolution and the origins of life

members included Jukes (an original candidate for EIC), Linus Pauling, Melvin Calvin, Mooto Kimura, John Maynard Smith, Alan Wilson, and Carl Woose. Many of the current AE's can trace their history to one or more of these founding editors. Zuckerkandl remained EIC until 1998 when he retired from active duty with the journal and passed the baton to Marty.

Marty's rein as EIC lasted from 1998 to last month, and I wish to extend my laudits to him for a remarkable job over those 15 years. He expanded the base of associate editors that were on the editorial board and brought in a very wide range of expertise. These AEs had to consider an increasingly broad array of manuscript subjects, as the discipline known as "molecular evolution" itself evolved and expanded at a breathtaking rate as we entered the genomic era. During this time too, many new and highly competitive publication venues became available to molecular evolutionists, and it is a testament to Marty's insight that $J M E$ has remained strong and vibrant over these years. Of course none of this could have been possible without the adroit assistance of two remarkable journal administrators that worked with Marty and all the AEs during this time: Ms. Connie Homan and Ms. Emily Hudson. I know Marty would join me in extending a heartfelt volley of gratitude to both Connie and Emily for all their hard work!

The original aims and scopes of $J M E$ spanned research between prebiotic chemistry and population genetics. Many of the papers published in the 1970s were experimental studies by chemists such as Leslie Orgel, Stanly Miller, and Juan Oró to recapilate the molecular events that led to the first proteins and nucleic acids. The fact that such researchers were a key target audience for the journal can be seen in Fig. 1. Here an advertisement in Die Naturwissenschaften for the first issue of $J M E$ can be found on the facing page immediately preceding the first paper of another cornerstone paper in the field, which was Manfred Eigen's (1971) treatise on the mathematical principles behind replicator selection. It was in this paper that the concepts of the quasi-species and the hypercycle were first 
introduced. These ideas, both their theoretical underpinnings and their empirical investigations fell within the first listed aim of the journal on "biogenetic evolution (prebiological molecules and their interaction)". Other aims of the journal at the time (Fig. 1) were listed as:

- Evolution of informational macromolecules (primary through quaternary structure).

- Evolution of genetic control mechanisms.

- Evolution of enzyme systems and their products.

- Evolution of macromolecular systems (chromosomes, mitochondria, membranes, etc.).

- Evolutionary aspects of molecular population genetics.

In the coming months and years, a few changes in the journal will be sought. First is that manuscript submission, tracking, and handling will now be handled through Editorial Manager (http://www.editorialmanager.com/jmev). Submissions will no longer be possible through Scholar One. The second is that the focus of the journal will in some ways be aligned more strongly with the original aims and scopes as listed above. A common theme that pervades the six original areas of focus is evolutionary mechanisms. Papers that seek to understand molecular evolutionary mechanisms that have the potential to transcend levels of organization will be especially encouraged. Studies performed using computational, chemical, in vitro, and experimental evolutionary methods, and those that target speciesindependent phenomena such as ribosomal function, genetic code evolution, and regulatory processes will occupy more of the journal space than before, with the consequence that work that is organism-, lineage-, or gene-specific will require a broader impact to be considered for publication. Other high-quality journals exist that specialize in molecular phylogenetics, conservation genetics, and population-level marker studies, to name a few, and it is not the intent of $J M E$ to reiterate these specialties directly. Consequently, a correlative change in the journal to this second point is that more papers may be rejected out of hand by an AE if they do not fit within the scope of the journal. This will serve to expedite the decision-making process for manuscripts. Third, the journal will solicit and welcome a greater number of review articles and editorial pieces. We will encourage submission and consider either short reviews on a topic ( $<3000$ words) or longer, more comprehensive reviews ( $>3000$ words). In addition, short notes suitable as a "letter to the editor" will also be considered for rapid publication of new ideas or concise experimental studies. In this vein, the "Random Walking" column that was written by Tom Jukes on various hot topics in molecular evolution will be revived, written by $J M E$ editors and guest editors alike. Lastly, the journal will welcome a new Journal Administrator, Ms. Anna Coleman-Hulbert, who (along with the EIC) can be reached by email at jme1@pdx.edu. We thank you for reading this and your continued support for the Journal of Molecular Evolution!

\section{References}

Bernardi G (2012) Fifty-year old and still ticking... An interview with Emile Zuckerkandl on the 50th anniversary of the molecular clock. J Mol Evol 74:233-236

Eigen M (1971) Self-organization of matter and the evolution of biological macromolecules. Naturwissenschaften 58:465-523

King JL, Jukes TH (1969) Non-Darwinian evolution. Science 164:788-798 